\title{
Port Hinterland traffic: modern planning IT methods
}

\author{
A. Radtke \\ IVE mbH - Ingenieurgesellschaft für Verkehrs - und Eisenbahnwesen \\ $m b H$, Germany
}

\begin{abstract}
This paper will present the latest requirements and methods of a sophisticated and integrated timetable and infrastructure planning tool. The related methodology, taking into accounts both passenger and freight services, will also be discussed. The paper will handle the planning and analysis of timetables, rolling stock, signalling and infrastructure, through the integration of operational simulation into the planning process. This will include:

- Timetable construction,

- Possession planning (timetable for construction sites),

- Capacity calculation (UIC 406),

- Railway operation simulation,

- Vehicle dynamic calculation/energy consumption,

- Infrastructure asset management and infrastructure planning and

- IT-Integration capability.
\end{abstract}

The port of Hamburg is one of the most important ports in Europe and is an important hub for international trading. The growth rate of the goods volume was increasing yearly until the year 2008. At that stage, the prognostic volume of the handling of goods will be doubled in some years. The railway is responsible for a high proportion of the transportation to and from the Hamburg port and other ports in Lower Saxony. Therefore, the number of daily trains running to and from the port will increase. However, the current railway infrastructure of the metropolis region of Hamburg and other regions in Lower Saxony, especially the track southwards, are already being used very intensively. The prognostic increase for the number of trains running in the network is expected to reach the capacity of the existing infrastructure. 
Keywords: timetable construction, railway planning methodology, IT integration.

\section{Introduction}

For Germany, it is of great importance to have a fully developed traffic infrastructure. It is not only an important aspect for the economical development of the country, but for the people with their need for mobility as well. Having, in particular, ecological factors in mind, it is impossible to follow the ongoing demand for newly build infrastructure. Therefore, the focus lies on a goaloriented transport policy that stresses the maintenance and optimization of the already existing traffic systems instead of prioritizing new developments.

The growth in the amount of traffic in the ports of Northern Germany, however, shows that the sole optimization of already existing railway infrastructure will not be enough to meet the traffic demands in the future.

Over the previous years, the German economy observed a constantly growing export volume, and the imports increased even more. Germany's external trade profited from the enlargement of the European Union over the last few years with numerous eastern European countries joining. The growth of the global economy and the German gross domestic product strengthened the external trade. These developments require increasing capacities of (railway) transporting.

Further development of the Northern German railway network was planned in a time when the long-distance passenger transport used to determine the direction of development. The realisation of the railway lines Cologne Frankfurt and Nuremberg - Ingolstadt was already finished.

\section{Targets and basic parameters of the investigations}

In Northern Germany, these developments increased the meaning of the big ports (Hamburg, Bremen, Bremerhaven and Wilhelmshaven). These ports play an important role when it comes to handling continental and intercontinental freight traffic. Handling capacities and storage areas - especially for the booming container handling - are enlarged to meet the needs of the increasing demand.

It is not only the accessibility from the seaside; the hinterland-connection plays an important role as well when it comes to handling the growing transport volume and economical developments in the future. Here, the rail freight traffic can be seen as the key factor.

A train's efficiency is mostly determined by the route. The axle load is important as well since it has a direct effect on the efficiency and the profitability of the freightage. A high line capacity is reached when all trains on one track travel at approximately the same speed. However, the efficiency of the track decreases with the growing differences of the maximum speed of trains. To counteract this development, a timely or regional separation of the individual 
types of trains can be used. Using a timely separation, fast trains operate during the day and slow trains at night. An optional regional separation differentiates between tracks for fast and slow trains.

Due to the fact that the railway infrastructure is rather durable, principles for the use have to be determined before the development of the original infrastructure. Civil engineering construction works like bridges, tunnels and the permanent way may have a life expectancy of more than hundred years. The rail track itself can be accounted with a life expectancy of up to 60 years. The specific characteristics of the line routing and the Control and Rail Automation Technology (needed for the safe and economical management) are comparatively expensive in the field of railway infrastructure. Planning dependability is needed when it comes to reasonable operation of railway infrastructure under the aspect of efficiency and sustainability. Traffic concepts have to be planned permanently and in the long run need to guarantee an efficient utilization of the railway construction. Above all, the permanent existence of infrastructure in a quality that is suitable and meets the technical requirements is to be guaranteed. Each year, investments have to be made to compensate for the wear and depletion that occurred during that year in order to guarantee the constant quality and availability of the track system.

Knowledge of the expected investments in the railway network enables companies working in the field of railway construction to predict and last their capacities according to the demands. It has to be differentiated between new construction, extension and renewal. The peculiarities of railway construction sites occur due to the wheel-rail system and especially when extending and renewing tracks. A long planning supply and a quick construction site operation are ideal to keep the railway operation and therefore are the core function of the railway company running as smooth as possible.

\section{Investigation area}

The various studies for the hub of Hamburg and other ports in Lover Saxony include the development of a different infrastructure and operational concepts for several time periods and a capacity analysis. The investigation area is described in Figure 1. The area is limited in the North by the border to Denmark, in the East by the stations Puttgarden, Schwerin, Ludwigslust and Magdeburg, in the South by the stations Osnabrück, Minden, Hannover and Braunschweig, and in the West by the stations Emden and Rheine [1].

The area contains railway infrastructure of the German Railway (DB Netz AG), of the Hamburg Port Authority (HPA), the East-Hannover Railway (OHE) and the Elbe-Weser Railway and Transportation Company Ltd. (EVB).

These studies examine the railway network and focus on the port-hinterlandtraffic. The investigation area covers the federal states of Lower Saxony, Hamburg and Bremen as well as parts of Schleswig Holstein, Saxony-Anhalt and North Rhine-Westphalia. Figure 2 shows exemplarily the railway tracks in the port of Hamburg. 


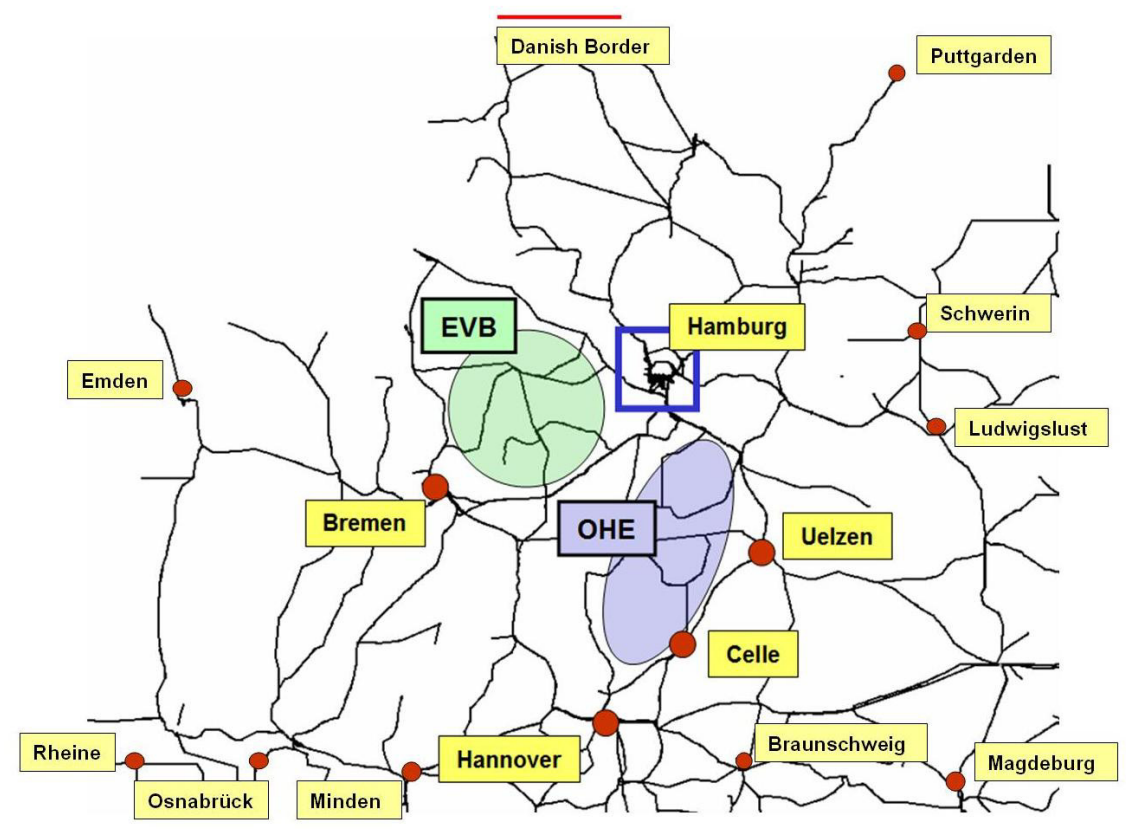

Figure 1: Investigation area (Puttgarden, Schwerin, Ludwigslust, Magdeburg, Osnabrück, Minden, Hannover, Braunschweig, Emden and Rheine).

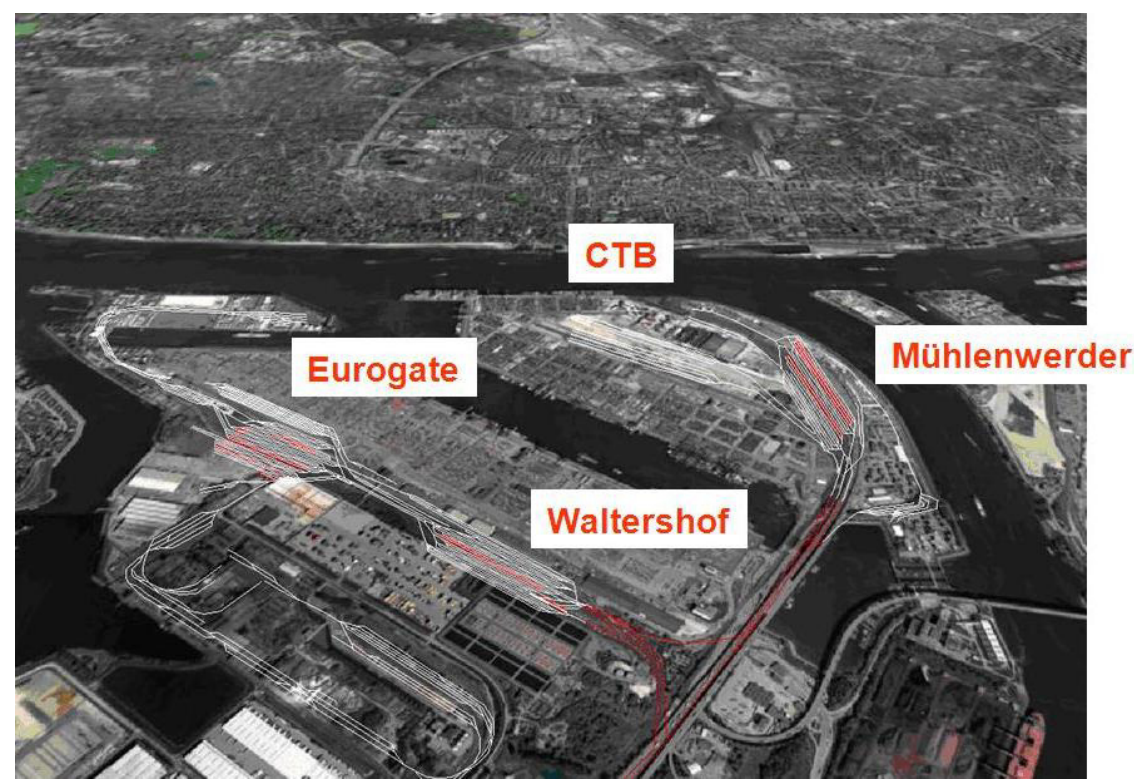

Figure 2: Hamburg Port Authority (source: Google Earth). 
Within the investigation area, a detailed analysis of the sub-networks, tracks and nodes was always combined with the consideration of requirements for the hinterland-traffic.

\section{Investigation railway line networks:}

- Hamburg - Hannover

- Node Hamburg

- Node Bremen

- Oldenburg - Wilhelmshaven

- Extension Hamburg S-Bahn Network

- Regio S-Bahn Network Lower Saxony/Bremen

In addition, models were used to represent how railway connections to the following ports could be made, taking existing and future traffic flows into account.

\section{Investigation area ports:}

- Hamburg

- Bremerhaven and Bremen

- Wilhelmshaven

- JadeWeserPort

- Emden

- Leer

- Papenburg

- Oldenburg

- Brake

- Nordenham

- Cuxhaven

- Stade

Afterwards, various single measures were by means with timetable construction and railway simulation separated and within the network connection analyzed. These were followed by a number of different questions. Models were used to test for example track extensions, the improvement of signalling equipment and changes of line routing.

\section{Development measures (examples only):}

- $\quad$ Stelle - Luneburg

- Y-Trasse

- $\quad$ Langwedel - Uelzen

- Oldenburg - Wilhelmshaven

- Uelzen - Stendal

- Oebisfelde - Stendal - Berlin

- Improved signalling equipment Stelle - Celle

- Multiple-track line extension Stelle - Uelzen - Celle 
- Line routing parallel to the Autobahn/Highway until Hamburg

- Use of secondary line in the area of Hamburg - Celle (see figure 1, $\mathrm{OHE}$ )

All analyses were conducted with the proven timetable construction and railway simulation tool, RailSys version $7 / 8$.

\section{The software tool}

\subsection{The software system RailSys}

RailSys is a comprehensive timetable construction and simulation package for various planning purposes. The system is used by various railway undertakings and a number of consultancy companies and universities around the world. RailSys is focussed on timetable construction and optimisation of timetables (capacity and performance), rolling stock utilisation, engineering design, and infrastructure management. The following sections highlight the main features only [2].

\subsubsection{Software history - RailSys}

The RailSys core system was developed by the Institute of Transport, Railway Construction and Operation (IVE) at the University of Hannover, Germany. The development of the first model started on mainframe computers using Fortran 77 in the eighties. This developed into a PC based model in 1996/1997, which was based on a new design and concept and was written in $\mathrm{C}++$ to make use of modern technology in a well structured new approach $(\mathrm{Simu}++)$. Object oriented, re-useable programming concepts were applied. At the moment (May 2010) RailSys version 8 is used at selected customers (RailSys Classic and RailSys Enterprise). Version 8 includes a database and multi user functionality. Several web-based services are also available such as RailSys Map and RailSys CRM (Customer Relationship Management) [3].

Figure 3 shows the main components of RailSys Classic and Enterprise:

RailSys Enterprise consists of the components shown above and two additional web-based modules. The component RailSys Map is used to visualize operational data (infrastructure and timetable data); the CRM-module can be used for third party requests concerning train paths.

The TOC request train slots and other information from the RIU. In the past, this process in general was a time consuming manual task using telephone, pen and paper or simple spreadsheets. The web based RailSys-CRM (Customer Relation Management) solution offers far more possibilities to support this process taking into account the increased time pressure for the planning tasks. TOC and RIU can save time of unnecessary (multiple) data entry and, therefore avoid mistakes. Furthermore, streaming less flow of data enables the RUI to perform the time table construction on the basis of the original requests and follows up changes in a much better quality to construct a non discriminating timetable. Using this technology, the RIU can provide all necessary information 


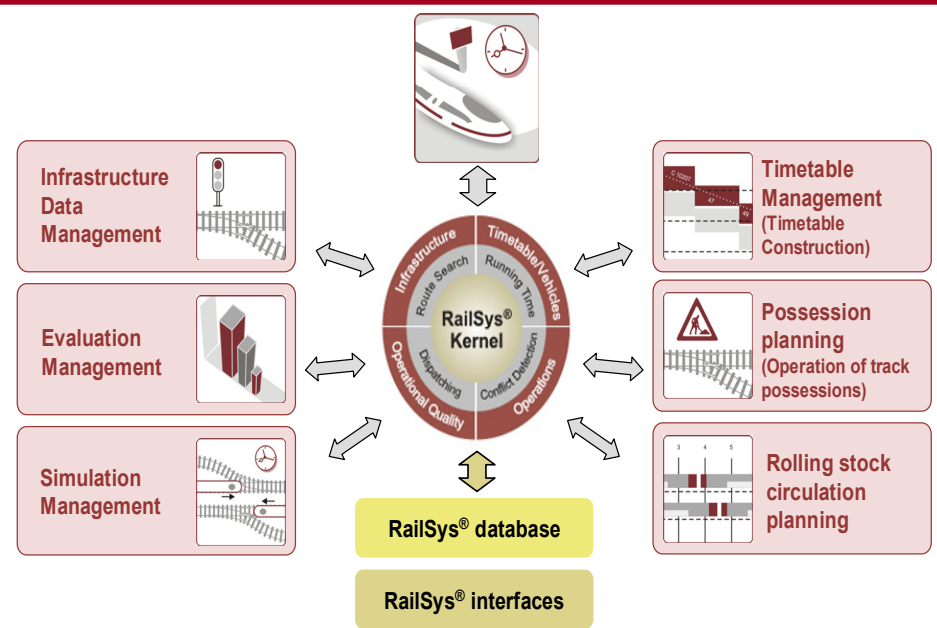

Multi User RailSys Enterprise for Timetable Construction, Simulation and Infrastructure planning

Figure 3: RailSys system (overview).

to rail regulation authorities to prove the non discriminating timetable construction according to the agreed timetable construction rules (see Figure 4).

\subsection{Workflow}

The exact microscopic modelling of the railway infrastructure with the RailSys System creates a database, which contains all tracks and all signalling systems information for the research area (see Figure 5). The infrastructure data is available in the RailSys data format (HPA), and had to be transformed by an interface (DB Netz AG) or integrated into the RailSys system manually (OHE and $\mathrm{EVB})$.

The timetable data on the infrastructure of the DB Netz AG was transformed from the timetable construction system RUT-K (DB Netz AG) into the RailSys data format. The timetable data on the infrastructure of the OHE and EVB was integrated in the RailSys system manually. The result is a base timetable which considers all passenger and freight train runs with information about arrival times, departure and dwell times at all stations in the research area.

The next step was the determination of existing and prospective bottlenecks for the metropolis region Hamburg and the hinterland (see chapter 3). Following this is the development of conflict solutions by operational or infrastructural measures. Furthermore, possible deviations and alternative routes were considered. 


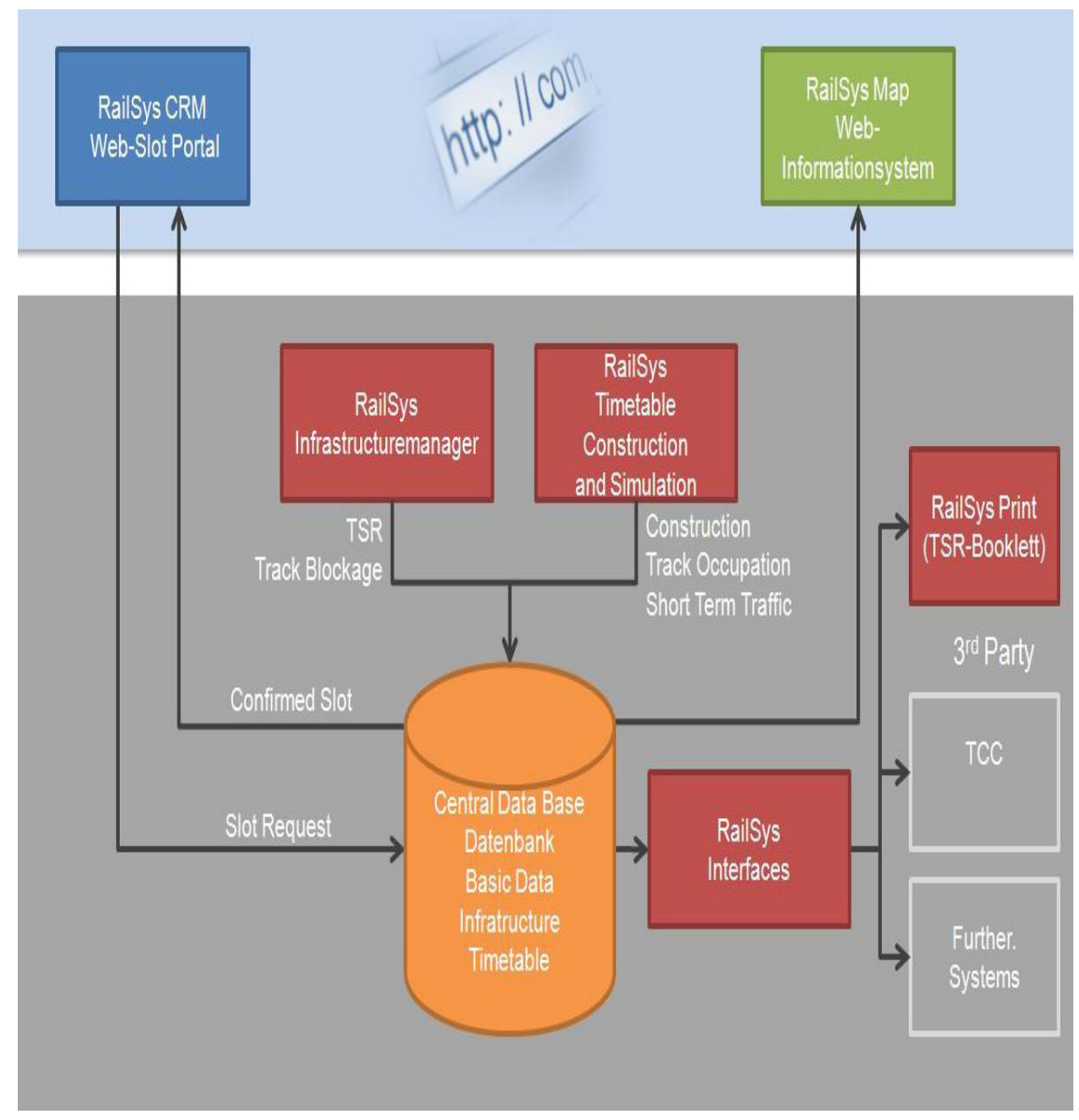

Figure 4: RailSys: consistent flow of data.

Various concepts will be developed for a step by step realisation of measures or a combination of measures which solve these bottlenecks. In the focus stands the realisation of short term measures with effects until 2015. However, long term measures until 2025 will be considered as well. The long term planning is important on the one hand to start with the planning in time to guarantee a realisation of these measures (realisation period in German is normally more than 10 years) and on the other hand to evaluate the sustainability of the short term measures.

The projects were partly dealt with in the multi user mode provided by RailSys Enterprise, so several persons could carry out the complex planning tasks at the same time.

Figure 6 shows an example of constructional operation partial planning, including some track blockings due to constructions. 


\section{Network of North Germany}

Port area

variant

dedicated freight lines

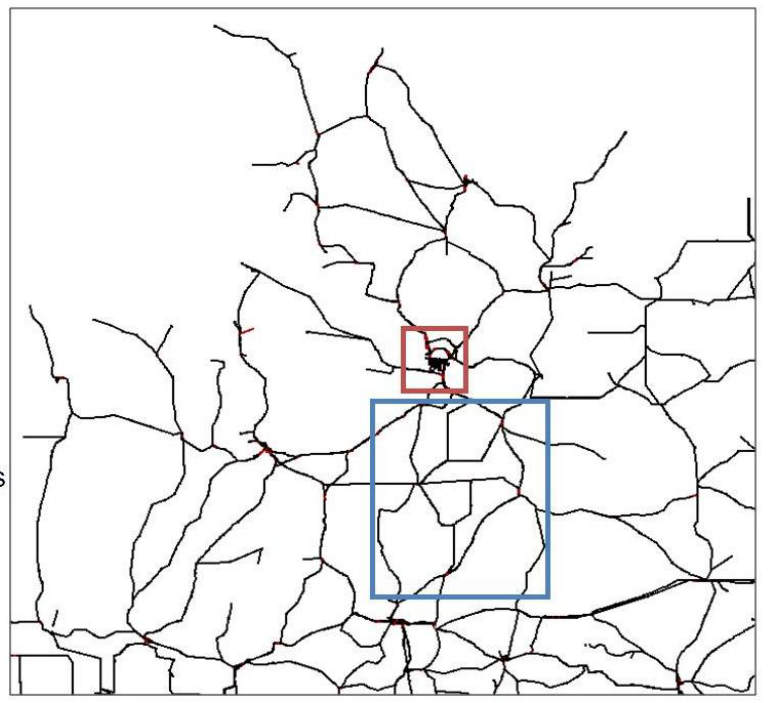

Figure 5: Railway network in RailSys of North Germany.

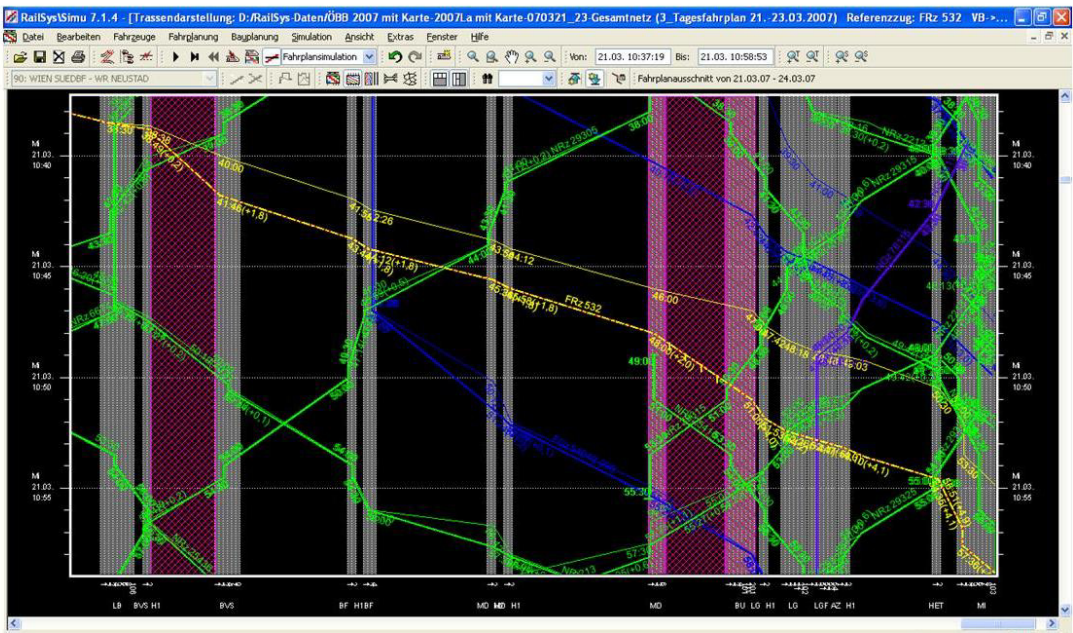

Figure 6: Example of constructional operation partial planning.

\section{Results and implementation}

The manifold results of these studies carried out with the use of modern IT technologies using the example of port-hinterland traffics can be summarized as follows:

- Detailed modelling of all infrastructure variants in networks and their effects 
- $\quad$ Timetable construction and simulation for all train runs in networks

- Infrastructure modelling and timetable construction supported by multi user technology

- Comparison of the possible conflict free number of train runs with the prognostic number of train runs for the time horizon 2011, 2013, 2015 and 2025 and the daily distribution

- Determination and analysis of bottlenecks and suggestion to solve these conflicts by operational or infrastructural measures

- Formulation of recommendations for the development of a future based and suitable infrastructure

According to the listed conditions and thoughts, the study introduces following results:

- The realised analysis of the current traffic densities and the expected increase in demand result in the outcome that the proposed Y-Trasse and the three-track extension on the route Hamburg - Hannover in the section Stelle - Lüneburg do not lead to the required increase in freight transportation capacity.

- To achieve a further increase in freight transportation capacity using the Y-Trasse, the extension of the section Lauenbrück - Buchholz from three to four tracks and in the region Isernhagen a connection to the track Celle - Lehrte is necessary

- Development measures serving as an alternative in enabling a capacity increase are introduced in this study.

- To improve the hinterland-connectivity of the ports of Bremerhaven and Bremen the "Bundesverkehrswegeplanung" plans various measures. All bottlenecks in the railway network cannot be eliminated but the planned measures can help improving the capacity of the track hinterlandconnectivity.

- As a short-term measure for capacity increase in the relation Hamburg Hannover an improvement of the signalling equipment could be used. Additionally, preparatory work could be done to redirect some trains on existing secondary lines.

- The three track extension between Stelle and Lüneburg will lead to another capacity increase in the medium term.

- It has to be decided now if the Y-Trasse should be realized in 2015 with the extensions shown in this study or if the requirements of the freight transportation should be followed, and therefore an alternative new constructed track meeting the needs of freight transportation should be realized between Hannover and Hamburg.

- $\quad$ The node Bremen has to be looked at much closer concerning the freight transportation coming from the ports in Lower Saxony and Bremen. According to today's information, extension measures are necessary.

- If the installation of a new S-Bahn-network in the region Bremen is decided, where no track infrastructure is planned yet, then the situation will be intensified. 


\section{References}

[1] Güterverkehr in Niedersachsen, Bauindustrie Niedersachsen/Bremen 2007, IVE

[2] Radtke, A. "Timetable management and operational simulation: methodology and perspectives", presentation of COMPRAIL 2006, Prag, Czech Republic, (2006), proceedings page $579-589$

[3] Timetable Construction and Simulation Tool RailSys ${ }^{\circledR}$ Enterprise and RailSys ${ }^{\circledR}$ Map and CRM: www.rmcon.de 